\title{
science \\ The 14th European Association of Science Editors Conference, Bucharest 2018
}

\author{
Sun Huh \\ Department of Parasitology and Institute of Medical Education, College of Medicine, Hallym University, Chuncheon, Korea
}

Date: June 8-10, 2018

Location: Faculty of Law of the University of Bucharest, Romania Theme: Balancing innovation and tradition in science editing

URL: http://www.ease.org.uk/ease-events/14th-ease-conference-bucharest-2018/

This year, I attended the biennial European Association of Science Editors (EASE) Conference for the fourth time. The previous conferences were held in Tallinn in Estonia, Split in Croatia, and Strasbourg in France. This year's conference was held in Bucharest, Romania. As in previous years, approximately 130 people registered for the conference. Most attendees came from various countries throughout Europe, while some editors attended from Asia and North America. Some representatives of large publishing companies attended, but most attendees were editors of academic journals or manuscript editors. As this was the fourth time in a row that I attended the conference, I readily adapted to its friendly and welcoming atmosphere.

On June 8th, a workshop with Crossref's Rachael Lammey was held from 9:00 a.m. to 2:30 p.m., with the theme of "XML for journal editors." First, coding in Journal Article Tag Suite (JATS) XML was demonstrated on the screen. Then, we went over the roles of CSS and XSL. A JATS XML file was validated to confirm that it met the rules and was edited if it had any errors. Rachael Lammey discussed Crossref's XML and various Crossref services. We had a total of 7 participants (Fig. 1); 1 participant did not attend the afternoon portion, so only 6 participants were captured in the photograph, along with the 2 lecturers. One participant was an IT specialist from Romania who shared with us the fact that JATS XML was used in Romania as well. The other participants were already using JATS XML for journal publishing but wanted to learn more, or were not using JATS XML yet but wished to implement it. All participants hoped to adopt JATS XML for journal publications, with the goal of implementing it on their websites and easily converting it to various other forms of XML. European journals used JATS

Received: July 13, 2018 Accepted: July 16, 2018

Correspondence to Sun Huh shuh@hallym.ac.kr

ORCID

Sun Huh

http://orcid.org/0000-0002-8559-8640
XML less than expected. Of the 34 countries in Europe, 13 did not have a single journal indexed in PubMed Central (PMC), 8 had a single journal indexed in PMC, and 9 had 10 or fewer published journals indexed in PMC. However, the countries with open-access journal publishers, such as England, Switzerland, Netherlands, and Germany, published 675 PMC-indexed journals. Compared to the 116 PMC-indexed journals in South Korea, it can be said that most European countries have a low number of journals using JATS XML. Although PMC 


\section{science editing /}

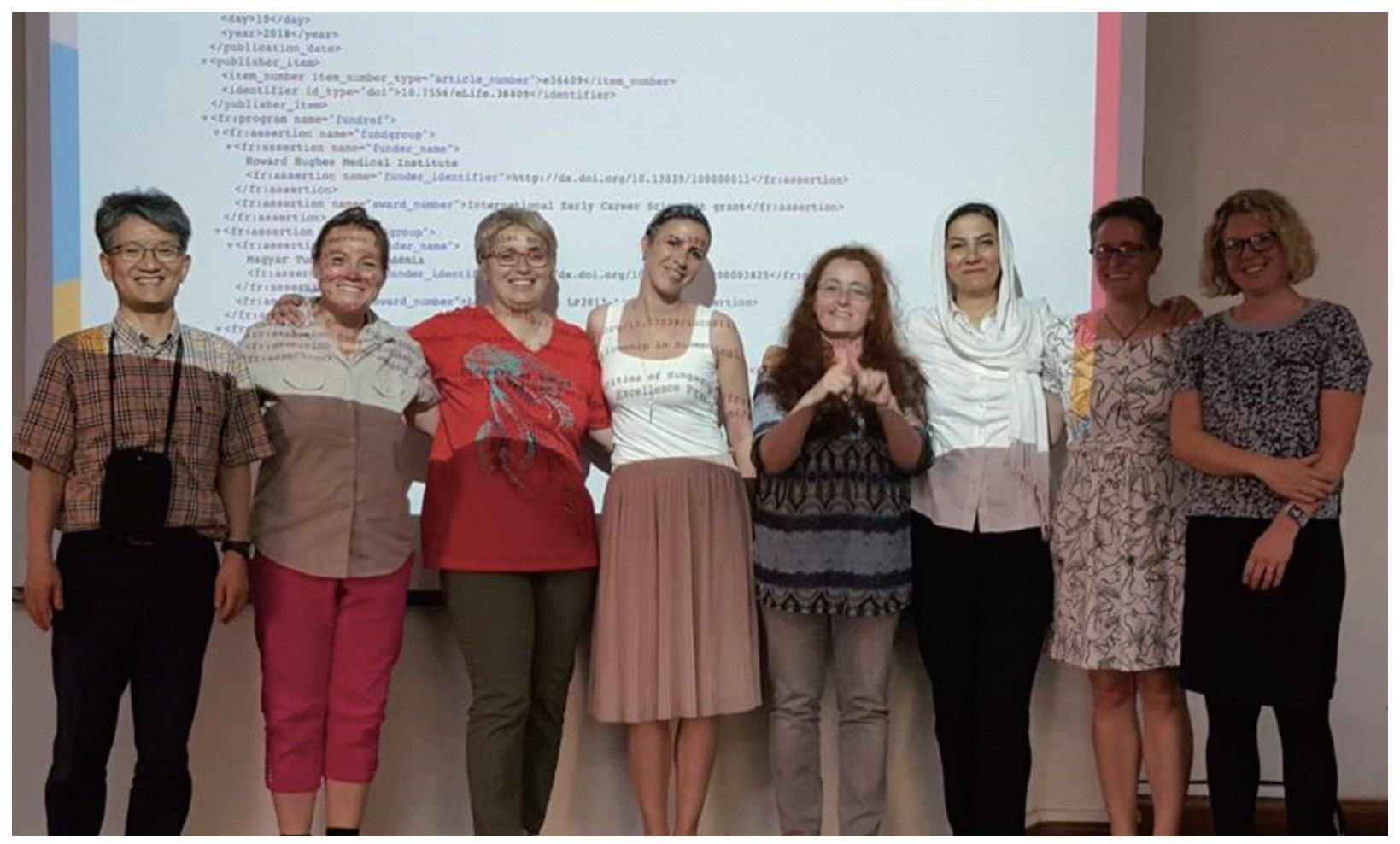

Fig. 1. "XML for journal editors" workshop participants. Background: Screen of XML code.

only archives biomedical and life sciences journals, it is expected to be not very different from other fields regarding the use of JATS XML. Taking this into consideration, it can be assumed that European journal editors either do not understand that JATS XML is an international standard in designing journal websites or they know that it is standard practice but have insufficient financial resources to adopt JATS XML. In comparison, most of South Korea's science journals use JATS XML and apply it to their websites, which indicates that South Korean journals are ahead of others in website design and/or the IT field. It was an exciting collaborative learning experience as a Korean editor to hold a workshop on an ITrelated field for European editors. A workshop with the same theme was held at the previous conference in Split, Croatia with 12 participants. At the conference held in Strasbourg, France, the workshop was cancelled because only 4 people wished to attend, but it reopened this year. I anticipate that South Korean editors will be of great help to European editors in this field.

The EASE Annual General Meeting and the first plenary lecture were held at 3:00 p.m. on June 8. A fiscal report was presented during the general meeting. The EASE conference is held every 2 years and the greatest expenditure is journal publication. The theme of the first plenary lecture was "Challenges of running a traditional journal," and examples from
Czech and Romanian journals were presented. During a conversation with Eva Baranyiova, the editor of a Czech veterinary and biomedical science journal, Veterinarni Medicina (https://vetmed.vri.cz), I learned that Korean scholars submitted the most articles to the journal and that the journal limits the number of publications because many were case study submissions. The editor asked whether I could suggest to Korean veterinarians that they should submit more original work upon my return to Korea. Since so many papers in this field are written by Korean authors, they cannot all be published in the Journal of Veterinary Research, which is the only Korean veterinary journal that is indexed in SCIE. As such, it is logical for Korean veterinary researchers to seek out opportunities to publish original research in other international journals. The conditions of many journals published in Eastern Europe are not that different from typical Korean journals. The main differences are that the Korean journals' websites more closely follow international journal standards and that European journals have a more multinational authorship, since article submissions come from many European countries.

Regarding the theme of innovations in journal publishing, Elisabeth Bowley presented on the open-access journal publisher model of Switzerland's Frontiers. Frontiers is an openaccess journal publisher that is well-known along with other 
publishers, such as PLoS, BioMed Central, Hindawi, and Dove, that have successful models. In addition, Mark Hester from Kudos (https://www.growkudos.com) explained the application of Kudos tools and metrics that accelerate research impact. Kudos expressed their interest in working together with Korean journals. Kudos promotes published articles through various social networking sites and readily provide information on citations and other metrics, in order to easily visualize an article's network. Pensoft \& Arpha Publishing Platform (https://arpha.pensoft.net) from Bulgaria introduced a next-generation publishing platform in which the entire process of publishing is all-inclusive on the website; an author can write and submit an article, which is then reviewed, published and archived, all on the same website. Biodiversity Data Journal (https://bdj.pensoft.net) was given as an example, and it was evident that its various functions were implemented using JATS XML. South Korea needs to build a this kind of cloud-based system that enables an all-inclusive system for writing, reviewing, editing, publishing, and archiving. Since this is difficult to achieve in the current circumstances in the publishing industry, with many small-scale publishers, academic societies need to collaborate and develop a cooperative model to keep up with these trends and advances.

"Setting up or improving your journal" was held on Sunday, June 10th, discussing administrative practices. Frontiers presented about establishing a new online open-access journal. Balkan Medical Journal explained its process of publishing, and topics on developing journals in Iran and the background and reasons behind moving a journal to a new publisher were also discussed. These issues have not been widely discussed in Korea; therefore, these practical administrative aspects should be explored to a greater degree to make progress.

The newly appointed President, Pippa Smart, presented on the EU's General Data Protection Regulation (GDPR) legislation, which recently went into effect in Europe on May 25th, and the "Principles of Transparency and Best Practice of Scholarly Publishing," which was updated in January 2018. Many editors in Korea are aware of the Best Practice guidelines, as this topic was also widely discussed in Korea, but issues on how to deal with the GDPR have yet to be explored with Korean editors. Private information under the GDPR includes information that can identify an individual, such as names and addresses; therefore, if a citizen of a European country participates in a journal submission system or is included on a website, it needs to comply with this law. Conferences should also adhere to the law; therefore, conferences that handle the information of citizens of European countries must abide by this regulation. Of particular note, the GDPR includes the "right to erasure (right to be forgotten)," which is something Korea has not often considered. Therefore, Korean editors need to consult professionals to understand the precautions that must be taken when Korean conferences handle the information of Europeans and to learn how to compose data protection and privacy policies. In addition, there was a session on data citation, and the results of a report on open data policy were presented (https://figshare.com/articles/The State_of_Open_Data_Report_2017/5481187/1). Additionally, the data deposit DOI (digital object identifier) of Crossref was introduced (https://www.crossref.org/blog/how-do-you-deposit-data-citations/). Furthermore, the data handling and ethics policies of Committee on Publication Ethics (https:// publicationethics.org/data) and the open data policy of the publisher Springer-Nature were introduced. South Korean journals rarely provide their data openly, and most journals have not implemented open data policies. It is time to examine what it means to share data and how it could help in the advancement of journals.

The final and fourth plenary lecture, "Innovations in publishing: beyond the journal," was delivered by Mark Patterson, the executive director of eLife Sciences, explaining how the various functions of journals have changed. During the lecture, Patterson discussed the introduction of preprinting, the emergence of an open-access mega journal that publishes tens of thousands of articles, the fact that over 1,000 journals are using the open journal system, and the development of ORCID (open researcher and contributor ID) and DORA (San Francisco Declaration on Research Assessment). Patterson also discussed how social changes influence the journal system by bringing along changes in many of its functions, except for unique features such as the peer-review evaluation system. He emphasized that when young scholars just embarking on their research are given the role of an editor or an editorial board member, the kind of motivation they receive is important. Patterson further discussed the future directions of journals based on his experience as a researcher and as someone who has played leading roles in multiple international journals, especially open-access journals. According to the content of this lecture, Korea's journals are on the right track. The only additional matter for Korean editors to consider is finding a way to compete with large-scale commercial publishers, because Korean journals are currently operated by individual academic societies. Western publishers and companies have continually made new and diverse models or platforms available to the Korean market, and Korea has been busy trying to catch up. If the role of the researcher, reviewer, and editor is to improve the quality of each article, platform development and management is the role of the publisher. The advancement of publishers will be the key for Korean journals to grow in a way that enables them to become internationally leading journals. We cannot lead if we are con- 
stantly trying to catch up with Western journal platforms.

Of the 12 posters, one that particularly stood out was a poster by Trakya University that analyzed the compliance of the 10 scholarly journals published by the University with the 16 items of "Principles of Transparency and Best Practice in Scholarly Publishing." Interestingly, none of their journals met the following 3 items from the guideline: marketing, intellectual property, and data sharing. The overall compliance was 49\%, indicating that the "Principles of Transparency and Best Practice in Scholarly Publishing" was relatively new to the journals published by the University and that measures could be taken to improve them. Although analogous research on Korean journals has not been conducted, the results are not expected to be very different from what that poster presented. Korean journals should be evaluated regarding these 16 items to make suggestions for additional improvements.
The EASE conference is held every other year for editors in Europe to share information with each other. The conference may be small, but it serves as a space for journals to make great strides in their development by inviting professionals from several fields, continuously providing new information, and enabling professionals to build close relationships with each other. It was nonetheless a superb chance to examine how European editors work on these issues. The date and location for the next conference has not been decided yet. I look forward to where I might be in 2 years.

\section{Conflict of Interest}

No potential conflict of interest relevant to this article was reported. 